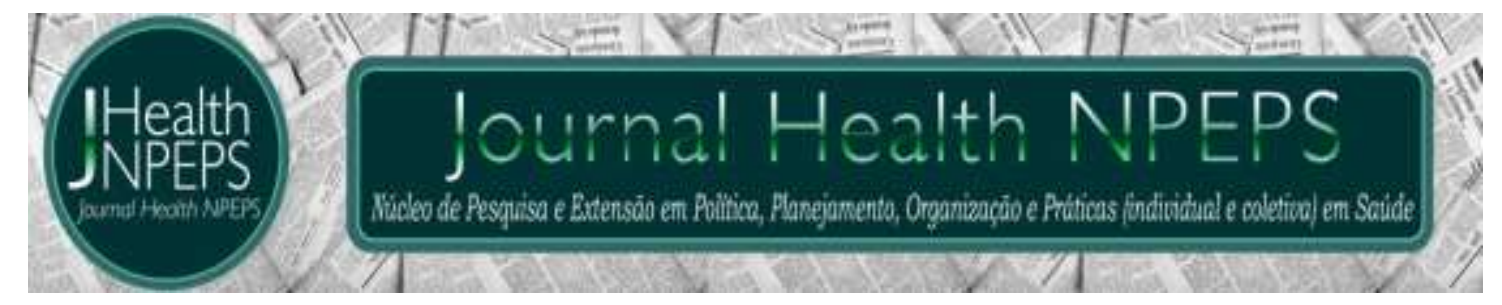

http://dx.doi.org/10.30681/252610104874

EDITORIAL

\title{
La pandemia de COVID-19 y sus violencias en América Latina
}

The COVID-19 pandemic and its violence in Latin America

A pandemia de COVID-19 e suas violências na América Latina

\section{Guillermina Díaz Pérez ${ }^{1}$}

El año 2020 será indeleble en la historia mundial, recordado por los estragos que en la vida de la humanidad trajo la pandemia mundial del nuevo coronavirus (SARS-CoV-2) causante de COVID-19 y los momentos convulsos que ha generado desencadenando múltiples violencias.

Etimológicamente la palabra violencia tiene su origen en el latín violentia, que significa "el que actúa con mucha fuerza", para los romanos deriva de vis, vires que remite a la fuerza, al vigor, el cual permite que la voluntad de uno se imponga sobre la de otro ${ }^{1}$, así cuando nos referimos a la violencia pensamos en acciones que afectan física o verbalmente. Sin embargo, la violencia, desde los estudios para la paz, no es un concepto limitado ni necesariamente implica acciones de agresión física o psíquica. Para Johan Galtung ${ }^{2}$, la violencia está presente "cuando los seres humanos se ven influidos de tal manera que sus realizaciones efectivas, somáticas y mentales, están por debajo de sus realizaciones potenciales". La violencia como podemos observar en esta concepción, no sólo se refiere a una forma de hacer, sino también de no dejar hacer, este autor la clasifica en tres tipos: violencia estructural, violencia directa

\footnotetext{
${ }^{1}$ Doctora en Ciencias Políticas y Sociales. Profesora Investigadora de la Facultad de Ciencias Políticas y Sociales de la Universidad Autónoma del Estado de México. Directora Editorial de Convergencia Revista de Ciencias Sociales de la citada universidad. Ciudad de Toluca, México. E-mail: diaz.guillermina@yahoo.com.mx ORCID ID: http://orcid.org/0000-0002-7634-6636
} 
y violencia cultural, las dos primeras modalidades serán abordadas centralmente en las siguientes líneas.

Galtung $^{2}$ considera a la violencia estructural como aquella que "está edificada dentro de la estructura y se manifiesta como poder desigual y consiguientemente como oportunidades de vida distintas (...) los recursos están desigualmente distribuidos", así, para Tortosa ${ }^{3}$ este tipo de violencia implica "situaciones de explotación, discriminación, marginación o dominación", que se traducen en pobreza de grandes masas, represión, clases antagónicas, violación de derechos humanos, alienación cultural, concentración del poder político, falta de democracia etc., lo cual invariablemente implica injusticia social.

En este sentido, podemos afirmar que Latinoamérica se ha caracterizado por una profunda violencia estructural en gran parte de su población, situación que se ha hecho aún más evidente ante la pandemia del COVID-19.

Desde la instauración del neoliberalismo como modelo económico en América Latina, dejó de ser prioritaria la inversión gubernamental en servicios de salud, e incluso en algunos países este derecho no es considerado como obligatorio en las prestaciones de todos los trabajadores. En la situación actual de pandemia, se hizo evidente la deficiencia estructural en la prestación de dichos servicios de salud, que ante la especificad de las necesidades para tratar a los enfermos de Covid-19 como respiradores, mayor número de espacios en unidades de cuidado intensivo, personal suficiente y capacitado, equipo de protección, por mencionar algunos; representaron una importante inversión que, en su mayoría, no estaba considerada en los presupuestos gubernamentales. La cantidad de personas que no cuentan con los recursos económicos para acceder a estos servicios agrava la situación, aunado a la saturación de los centros de salud y las deficiencias para atender a una gran cantidad de enfermos.

El grado de marginación y pobreza en el que vive gran parte de la población latinoamericana, los hace aún más vulnerables a contraer el virus y lograr sobrevivirlo, por ello Tortosa ${ }^{4}$ denomina al COVID-19 como el "virus selectivo", no sólo porque en un primer momento afecta aún más a las personas con padecimientos crónicos y a los adultos mayores de 60 años, también porque las personas en situación de pobreza, difícilmente sobrevivirán al mismo, entre otras cuestiones porque suelen padecer desnutrición y/o enfermedades crónicas, así 
como falta de acceso al servicio médico. Aunado a ello, la pandemia ha generado una profunda crisis económica que ha producido mayor desempleo, acrecentando y agudizando la violencia estructural en la región.

Las secuelas en la salud de algunas personas que han padecido el virus, requieren de atención médica permanente y para ello necesitan acceso a los servicios de salud, lo que en el futuro cercano se ve poco probable.

Asimismo, el acceso limitado a las pruebas para determinar si una persona es portadora del virus SARS-CoV-2 y la enfermedad COVID-19, ha jugado un punto clave en su propagación; primeramente, porque la falta de pruebas impide un rastreo sanitario eficiente ante posibles focos de expansión del virus para tratar de mitigarlo, aunado a que hay evidencia de miles de personas que fallecieron sin que se determinara a través de una prueba si dicho virus fue el causante de su deceso, el protocolo de seguimiento se ve limitado pues tampoco se aplican pruebas a las personas que estuvieron en contacto con el occiso.

A la falta de capacitación en torno a las medidas de control para que no se esparza la infección del virus, hay que sumar que el personal sanitario no siempre tiene acceso gratuito y libre a pruebas diagnósticas -prestación con la que también deberían contar sus familias- y en caso de contagio, pocos han recibido apoyo para aislarse de su círculo cercano, teniendo ellos que subsanar los gastos.

Ante la magnitud de esta pandemia, al igual que en otras regiones del mundo, en la mayor parte de los países de América Latina no se cuenta con suficientes especialistas en el área de la salud -neumólogos, epidemiólogos, internistas, especialistas en cuidados intensivos- para atender la emergencia en la que estamos inmersos, ante ello, personal no especializado se ha sumado a la atención de los enfermos de Covid-19. Se visibiliza aún más la violencia estructural que se vive, si se considera que a pesar del papel central que tienen los profesionales de la salud y todo el personal sanitario, no han sido protegidos, gran parte de ellos han prestado sus servicios sin contar con el adecuado y suficiente equipo de protección que les permita evitar contraer el virus, en el mejor de los casos lo han adquirido con sus propios recursos, situación que ha sido denunciada por profesionales de la salud a través de manifestaciones públicas y en redes sociales. 
Durante más de seis meses el personal de salud ha sufrido un fuerte desgaste físico y psicológico; en algunos casos -los mínimos-, lejos de ser reconocidos por su entrega y trabajo, han sufrido agresiones físicas y verbales, llegándoles a impedir el acceso al transporte público.

Esta falta de seguridad y abandono en el que labora gran parte del personal del sector salud gubernamental en algunos países de América Latina, nos remite a la violencia directa, a "aquellas situaciones (...) en que una acción causa un daño directo sobre el sujeto destinatario, sin que haya apenas mediaciones que se interpongan entre el inicio y el destino de las mismas" ${ }^{5}$. Así, la violencia directa puede manifestarse de manera física, psicológica o verbal; en este sentido podemos considerar como parte de la violencia directa derivada del COVID-19, la muerte de personal que laboraba en el sector salud, que ocurre en gran medida por no contar con la protección y/o con la capacitación necesaria para evitar contagiarse. Al respecto, Amnistía Internacional ${ }^{6}$ analizó la información disponible de 79 países, registrando al menos 7,000 muertes de personas trabajadoras de la salud, destacando que tres países de Latinoamérica registraron cifras particularmente altas: México (1,320), Brasil (634) y Perú (183), el primer país tiene la tasa más elevada a nivel mundial de muertes de personal del sector salud.

De igual forma, la pandemia del COVID-19 ha dejado sin posibilidad de estudiar a niños y jóvenes de todas las edades, que no cuentan con la tecnología para acceder a clases en línea o por televisión o incluso no tienen energía eléctrica, la pregunta es si al finalizar la pandemia, la situación económica familiar les permitirá regresar a la escuela. A pesar del riesgo que puede implicar, existe un número considerable de niños que permanecen solos en sus casas, sin la supervisión y cuidado de los padres que enfrentan la necesidad de salir a trabajar y la imposibilidad de que otras personas asuman su cuidado.

Para la población que vive al día, el poder realizar un confinamiento, resguardarse en sus casas, no es una opción (tampoco lo es para las personas en condición de calle, muchas de ellas niños), el salir a trabajar ofreciendo servicios y vendiendo diversidad de productos, es lo único que les permitirá acceder a recursos para alimentar a sus familias ese día.

La pandemia también ha violentado la salud mental de las personas, por el aislamiento social que se suma al estrés financiero, el miedo, la incertidumbre, la 
angustia y la ansiedad que afectan de manera diferenciada a los grupos etarios, a los géneros y los estratos socioeconómicos, su impacto en la región, aún no es conocido, pero es claro que la atención psicológica debe tener un lugar central.

Quienes padecen o han padecido el COVID-19, no sólo son víctimas de esta enfermedad, también sufren de discriminación y/o marginación social, que los ha llevado a perder sus empleos o ser obligados a cambiar de residencia, por lo que frecuentemente ocultan el estar o haber estado contagiados. Dicha marginación en ocasiones, también es padecida por los deudos de las 294,174 personas que oficialmente habían muerto en América Latina por Covid-19 hasta el 8 de septiembre de $2020^{7}$.

Ante el confinamiento por la pandemia, la casa, no es siempre un lugar seguro para las personas, por el contrario, puede ser el espacio en el que la violencia sea una constante e incluso encuentren la muerte, dan cuenta de ello la violencia intrafamiliar, la violencia contra las mujeres -denominada la otra pandemia silenciosa - y el feminicidio, que ante esta emergencia sanitaria se han incrementado, ONU Mujeres ${ }^{8}$ registra que en América Latina, en promedio una de cada tres mujeres a lo largo de su vida es violentada y durante 2019, se perpetraron 3,800 feminicidios, si bien estos números son altos, ONU Mujeres considera que este problema social está subestimado y que la pandemia lo está agravando, la información que dispone esta organización señala que la violencia contra las mujeres se ha incrementado durante la pandemia en Bolivia, Argentina, Brasil, Colombia y México.

Por otra parte, los servicios públicos que se prestaban para prevenir, atender y sancionar la violencia contra las mujeres han disminuido por la propia situación de confinamiento, aunado a que los recursos están enfocados en atender la pandemia; asimismo, organizaciones de la sociedad civil que trabajan en torno a este problema público, también enfrentan dificultades para ofrecer sus servicios.

La violencia cultural permite legitimar las violencias tanto directa como estructural, hace que se perciban como correctas o al menos como no erróneas, así refiere a la esfera simbólica de nuestra existencia, a la que pertenecen la ideología, la religión, el arte, la ciencia formal, etc. que puede ser usadas para legitimar cualquier tipo de violencia9. Ante la pandemia los líderes políticos, pueden ejercer esta violencia cuando no asumen públicamente para sí mismos, ni 
reafirman para la población las recomendaciones sanitarias para evitar la propagación del virus.

La pandemia del COVID-19 y sus violencias, nos permite reflexionar sobre lo que es prioritario en la vida, desde la ética del cuidado, los gobiernos y las personas tienen la obligación moral de cuidar de los otros y de sí mismos, hoy más que nunca el cuidado debe ser el valor central en nuestras vidas, no puede existir la justicia social sin que la población en general cuente con los elementos mínimos para ejercer este valor, parafraseando a Comins ${ }^{10}$ es prioritario recuperar la capacidad humana de preocupación y cuidado como elemento central para construir la paz y lograr sobrevivir a esta pandemia mundial.

\section{REFERENCIAS}

1. Soca R. El origen de las palabras, diccionario etimológico ilustrado. Argentina: Del Nuevo Extremo; 2018.

2. Galtung J. Investigaciones teóricas. Sociedad y cultura contemporáneas. Madrid: Tecnos/Instituto de Cultura Juan Gil-Albert; 1995.

3. Tortosa JM. Sociología del sistema mundial. Madrid: Tecnos; 1992.

4. Tortosa JM. "Virus Selectivo" en Blog Sobre el Mundo Mundial (actualizado 8 abril 2020; citado 29 agosto 2020). Disponible en: https: / / mundomundialtortosa.blogspot.com/search?q=virus+selectivo

5. Jiménez BF, Muñoz F. Violencia estructural. En López M. (director.) Enciclopedia de Paz y Conflictos. Granada, España: Instituto de la Paz y los Conflictos, Universidad de Granada; 2004.

6. Amnistía Internacional Global. Análisis de Amnistía Internacional revela que más de 7 mil personas trabajadoras de la salud han muerto a causa de COVID-19 (actualizado 3 septiembre 2020; citado 5 septiembre 2020). Disponible en: https://amnistia.org.mx/contenido/index.php/global-analisis-de-amnistiainternacional-revela-que-mas-de-7-mil-personas-trabajadoras-de-la-salud-hanmuerto-a-causa-de-covid-19/

7. Pan American Health Organization. Cumulative confirmed and probable COVID19 Cases Reported by Countries and Territories in the Region of the Americas 
(actualizado 8 septiembre 2020; citado 8 septiembre 2020). Disponible en: https://ais.paho.org/phip/viz/COVID19Table.asphe Americas

8. ONU Mujeres. Prevención de la Violencia Contra las Mujeres Frente A Covid-19 en América Latina y el Caribe (actualizado 20 abril 2020; citado 6 septiembre 2020). Disponible en https://www2.unwomen.org//media/field\%20office\%20americas/documentos/publicaciones/2020/05/es_pre vencion\%20de\%20violencia\%20contra\%20las\%20mujeresbrief\%20espanol.pdf?la=es $\notin v s=3033(06 / 09 / 2020)$

9. Galtung J. Peace by peaceful means. Peace and conflict, development and civilization. Oslo: International Peace Research Institute (PRIO); 1996.

10. Comins MI. Horizontes epistemológicos de la investigación para la paz: una perspectiva pazológica y de género. En: García-González DE. Enfoques contemporáneos para los estudios de paz. México: Tecnológico de Monterrey Conacyt; 2018.

Como citar: Díaz-Pérez G. La pandemia de COVID-19 y sus violencias en América Latina. J Health NPEPS. 2020; 5(2):1-7. 